\title{
THE ORGANIZATION OF THE ROSETTA GRAMMARS
}

\author{
Jan Odijk \\ Philips Research Laboratories, P.O. Box 80.000 \\ 5600 JA Eindhoven, The Netherlands
}

\begin{abstract}
In this paper the organization of the grammars in the Rosetta machine translation system is described and it is shown how this organization makes it possible to translate between words of different syntactic categories in a systematic way. It is also shown how the organization chosen makes it possible to translate 'small clauses' into full clauses and vice versa. The central concept worked out here in some detail is the concept of 'partial isomorphy' between subgrammars. The system as described here has been implemented and is currently being tested.
\end{abstract}

\section{ROSETTA}

In this section I will mention some essential properties of the Rosetta machine translation system. For more extensive descriptions of this system I refer to Landsbergen(1987), Appelo \& Landsbergen(1986), Appelo, Fellinger \& Landsbergen(1987) and Leermakers \& Rous(1986).

The Rosetta machine translation system is an interlingual machine translation system based on Montague Grammar and developed at Philips Research Laboratories in Eindhoven for Dutch, English and Spanish. The grammars used in Rosetta are computational variants of Montague Grammar and are called M-grammars.

Rules in M-grammars, called M-rules, operate on syntactic surface trees. If a certain string str is associated with a syntactic tree of category $C$ the notation $C($ str $)$ will be used.

An M-grammar in Rosetta is subdivided into a number of subgrammars. Each subgrammar is a rule package and is defined by specifying a head (the category of a designated argument from the import for the subgrammar), export (the categories of the syntactic trees yielded by the subgrammar) and a control expression that indicates in whicl order M-rules must be applied.

In Rosetta3 ${ }^{1}$ a distinction is made betweer meaningful M-rules, called rules (that corresponc to a meaning operation), and meaningless rules called transformations (that do not correspond te a meaning operation).

M-grammars are reversible. Because of this fact the translation relation between two sentences car be illustrated by showing their derivations in gen. eration. The example derivations below will be restricted to generation only.

Within the Rosetta system the grammars of thi relevant languages are attuned to one another in such a way that two sentences that are eacl other's translation can be derived starting from corresponding basic expressions by applying corre sponding rules in the same way for both sentences 'Corresponding' here means: 'corresponding to th' same meaning operation or basic meaning', and i loolds of meaningful M-rules only.

M-grammars attuned in this way are called iso morphic grammars, and therefore the method o translation used is called the isomorphic gramma approach to machine translation.

\section{CATEGORIAL MISMATCHES}

In order to derive simple sentences e.g. Ziet hij $d$ man? one could design a grammar of Dutch that starting with a basic verb (zie) applies rules to de rive the sentence mentioned. One could have rule combining a basic verb with arguments that it al lows or requires (hij, de man) in a sentence, rule that determine the tense of this sentence (presen tense) and rules that determine 'mood' and real

\footnotetext{
${ }^{1}$ The paper deals with the grammars in the third versio of the Rosetta system, Rosetta3.
} 
ize the sentence accordingly ( in this case yes-noquestion, main clause, realized by the order verbsubject-object), etc.

In order to derive the English sentence Does he see the man? as a translation of this Dutch sentence it would be required to design a grammar of English isomorphic to the grammar of Dutch sketched above. There must be a rule combining a verb (see) with its arguments (he, the man). There must be rules determining tense and aspect (simple present tense in the example sentence), and there must be rules that determine 'mood' and realize the sentence accordingly (yes-no- question, main clause, realized by introducing the auxiliary verb $d o$ and the order $d o$-subject-verb-object), etc..

In this simple example the syntactic categories of the Dutch word zien and its translation into English see are the same. For these cases isomorphic grammars can be developed rather straightforwardly.

However, machine translation systems must be able not only to translate between words of the same category, but also to translate between words of different syntactic categories. Some examples where a translation between words of different categories is required or desirable are given in the following table:

\begin{tabular}{|l|}
\hline lij zwemt graag (Adv) \\
he likes to swim (Verb) \\
\hline hij is toevallig ziek (Adv) \\
he happens to be ill (Verb) \\
\hline het mist (Verb) \\
it is foggy (Adj) \\
\hline hij schaamt zich ervoor (Verb) \\
He is ashamed of it (Adj) \\
\hline hij is mij 3 gulden schuldig (Adj) \\
He owes me 3 guilders (Verb) \\
\hline hij is in A'dam woonachtig (Adj) \\
He resides in Amsterdam (Verb) \\
\hline Het is voldoende (Adj) \\
It suffices (Verb) \\
\hline
\end{tabular}

The Rosetta grammars must be able to deal with such cases in a systematic way.

It must also be possible to translate 'small clauses' into full clauses (finite or infinite) and vice versa. 'Small Clauses' are propositional units in which a subject-predicate relationship is expressed and which are not marked for tense and aspect (cf. Stowell (1981)). Some examples of full clauses and their corresponding 'small clauses' are given in the following table:
'Full Clauses'

\begin{tabular}{|l|l|}
\hline Verb & He killed a man \\
Adj & He is intelligent \\
Prep & He is against the deal \\
Adv & He is here \\
Noun & He is a fool \\
\hline
\end{tabular}

'Small Clauses'

\begin{tabular}{|l|l|}
\hline Verb & I had the man killed \\
Adj & I consider him intelligent \\
Prep & We got him against the deal \\
Adv & We got him here \\
Noun & They consider him a fool \\
\hline
\end{tabular}

Small clauses can occur only as complements within a clause. The fact that they are not marked for tense and aspect is reflected in the absence of auxiliary and copular verbs. If the grammar allows for translation of clauses into small clauses and vice-versa, then it becomes possible to derive e.g. he seems ill and hij schijnt ziek te zijn (lit. he seems to be ill as translations of each other. It is sometimes required to be able to translate small clauses into full clauses in some cases. The English sentence he seems ill cannot be translated into Dutch *hij schijnt ziek, which is ungrammatical, but must be translated into hij schijnt ziek te $z i j n$ ( he seems to be ill) or into het schijnt dat hij ziek is (it seems that he is ill).

\section{GRAMMAR ORGANI- ZATION}

The global organization of the grammars (leaving transformations out of consideration) is the same for all languages, as is required by the isomorphic method.

The grammars are subdivided into five projection subgrammars ${ }^{2}$, one for each major category (Verb, Noun, Prep, Adj, Adv). ${ }^{3}$

Each of these projection subgrammars consists of a number of subgrammars. The partitioning of projection subgrammars into subgrammars is motivated by the fact that it must be possible to use the output of each subgrammar as import to subgrammars of other projection subgrammars.

A schematic representation of the partitioning of a projection subgrammar into subgrammars is

\footnotetext{
${ }^{2}$ These are called subgrammaro in Appelo, Fellinger \& Landsbergen(1987)

${ }^{3}$ Apart from these subgrammars there is also a projection subgrammar to derive simple $N P s$, which is not partially isomorphic to the other projection subgrammars.
} 
given in figure 1 , where $X$ is a variable over the major syntactic categories. A projection subgrammar is a set of subgrammars that define a projection for a given category $X$. A projection of some category $\mathrm{X}$ is a syntactic structure headed by $\mathrm{X}$.

Each projection subgrammar is bifurcated as indicated in figure 1 . If the rules and transformations in the XPPtoCLAUSE and CLAUSEtoSENTENCE subgrammars are applied a full clause is derived. If the rules and transformations of the XPPtoXPFORMULA (XPPtoXPF) and XPFORMULAtoXPP (XPFtoXPP) are applied a 'small clause' is derived.

The projection subgrammars are partially isomorphic to one another, which makes it possible to translate a subset of constructions from one projection subgrammar into constructions from some other projection subgrammar. Furthermore the XPPtoXPF subgrammars are partially isomorphic to the XPPtoCLAUSE subgrammars, and the XPFtoXPP subgrammars are partially isomorphic to the CLAUSEtoSENTENCE subgrammars. This makes it possible to translate a subset of full clauses into 'small clauses'.

The subgrammars are partially isomorphic to one another instead of fully isomorphic, because for certain full clauses no corresponding small clauses exist (e.g. there is no 'small clause' corresponding to the full clause Is he ill?).

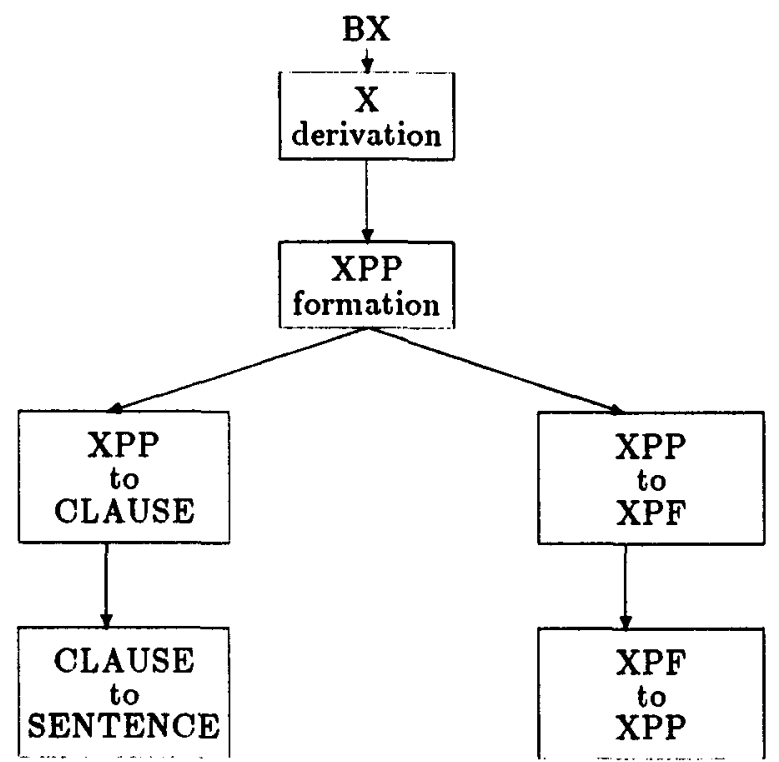

Figure 1: The global organization of the Rosetta projection subgrammars. $X$ is a variable ranging over the major syntactic categories
The subgrammars indicated in figure 1 will be discussed in more detail now.

X-Derivation subgrammar deals with deriva. tion and composition

XPPformation In this subgrammar the argu ment structure and the syntactic realizatior of arguments (whether they are subject, ob ject, prepositional object, etc.) is accounted for. Voice (active, passive) is determined ir this subgrammar.

XPPtoCLAUSE When this subgrammar is ap plied a full clause will be derived. In the sub. grammar propositional complements and ad. verbials are introduced, tense and aspect is determined and auxiliaries are introduced ac. cordingly. There are several transformation: in this subgrammar to deal with the propel incorporation of propositional units into the structure, e.g. transformations dealing witl control phenomena, and transformations deal. ing with the proper positioning of verbs (es pecially in Dutch). 'Hidden' arguments, e.g nonovert by-phrases in passives, are dealt witl here.

XPPtoXPF When this subgrammar is applied 'small clause' will be derived. The XPPtoXPF subgrammars are partially isomorphic to the XPPtoCLAUSE subgrammars, hence the contain similar corresponding rules. The contain rules introducing propositional com plements, rules determining tense and aspec (which is considered to be present thougl dependent upon superordinate clauses) anc rules dealing with hidden arguments.

CLAUSEtoSENTENCE In this subgramma nonpropositional arguments are introducec and scope of quantificational expressions is ac counted for. Furthermore the 'mood' of a sen. tence is determined, i.e. it is decided whether it is going to be a declarative, interrogative relative etc. clause.

XPFtoXPP This subgrammar is partially iso morphic to the CLAUSEtoSENTENCE sub. grammars. It contains rules to introduce non propositional arguments and to account fo. scope. There are 'mood' rules determining whether the XPP is 'closed' (i.e. there are ne free variables left in the structure), or 'open' (i.e. the subject variable is free). 


\section{ILLUSTRATIONS}

The global organization of the grammar will be illustrated here by showing the derivation processes of certain examples involving a categorial mismatch and of some examples of translations from 'small clauses' into full clauses or vice versa. I repeat that only the generative part of the derivation need be demonstrated given the reversibility of the grammars. Furthermore only the correct derivation paths through the grammar will be illustrated, though in reality many false paths, i.e. paths through the grammar that do not lead to an actual sentence, are chosen by the grammar.

Since M-grammars are reversible it possible to 'translate' from e.g. Dutch into Dutch. In this way Rosetta functions as a paraphrase generator. Because of this, the partial isomorplyy between two projection subgrammars can (and will) be illustrated by showing the parallel derivation of two paraphrases in generation.

In subsection 4.1 the derivation of hij schaamt zich ervoor and he is ashamed of it will be illustrated.

In subsection 4.2 the derivation of I find him intelligent and $I$ find that he is intelligent will be illustrated.

In subsection 4.3 the derivation of he seems intelligent, he seems to be intelligent and it seems that he is intelligent as paraphrases of one another will be illustrated.

In subsection 4.4 the derivation of de op haar verliefde man and de man die op haar verliefd is as paraphrases of one another will be illustrated.

In subsection 4.5 the derivation of hij zwemt graag and he likes to swim will be illustrated.

\subsection{Adjective-Verb}

The derivations of hij schaamt zich ervoor (lit. he ashamed himself therefor) and its translation he is ashamed of it run as follows. The verb schamen is a two place verb so that it can be combined with two variables, $x_{1}$ and $x_{2}$, in the VPPformation subgranmar yielding $\operatorname{VPP}\left(x_{1} x_{2}\right.$ schaam $)$. In the English grammar, the adjective ashamed is also combined with two variables in the ADJPPformation subgrammar, yielding $\operatorname{ADJPP}\left(x_{1}\right.$ ashamed $x_{2}$ ). The Dutch verb schamen must realize its second argument as a prepositional object with the preposition voor. The English adjective ashamed must realize its second argument as a prepositional object as well, though headed by the preposition of. Pattern transformations are applied to yield this effect: $\operatorname{VPP}\left(x_{1}\right.$ voor $x_{2}$ schaam $)$ and $\operatorname{ADJPP}\left(x_{1}\right.$ ashamed of $\left.x_{2}\right)$.

In the VPPformation suhgrammar a Voice-rule applies determining that the structure is in active voice. In the ADJPPformation subgrammar a corresponding rule applies which has no visible effects.

In Dutch a transformation spelling out a reflexive pronoun must apply, since the verb schamen is a so-called inherently reflexive verb. This yields $\operatorname{VPP}\left(x_{1}\right.$ zich voor $x_{2}$ schaam $)$. Since spelling out these reflexive pronouns is achieved by transformations, no corresponding M-rule need apply in English.

These structures are both input to the XPPtoCLAUSE subgrammar where they are turned into clauses. In Dutch this yields CLAUSE $\left(x_{1}\right.$ zich voor $x_{2}$ schaam). In English the copula be is introduced, yielding CLAUSE $\left(x_{1}\right.$ be ashamed of $\left.x_{2}\right)$. Tense and aspect rules are applied in both cases, putting the structures in present tense, yielding CLAUSE $\left(x_{1}\right.$ zich voor $x_{2}$ schaamt $)$ and CLAUSE $\left(x_{1}\right.$ is ashamed of $x_{2}$ ).

Substitution rules substitute the NPs het and it respectively for the variables $x_{2}$ and the NPs $h i j$ and he respectively for the variables $x_{1}$. This yields in English CLAUSE(he is ashamed of it) and in Dutch CLAUSE(hij zich voor het schaamt). An obligatory transformation turns voor het in Dutch into ervoor.

Mood rules are applied in Dutch and in English. The clauses are turned into declarative main clauses. In English this yields SENTENCE(he is ashamed of it) and in Dutch this yields SENTENCE(hij zich ervoor schaamt). Application of the transformation putting the finite verb in 'second' position and application of an obligatory topicalization transformation in Dutch yield the actual sentence Hij schaamt zich ervoor.

\subsection{Adjective-declarative clause with main verb}

The parallel derivations of I find him intelligent and $I$ find that he is intelligent run as follows. In the ADJPPformation subgrammar the adjective intelligent is combined with a variable $x_{1}$ yielding $\operatorname{ADJPP}\left(x_{1}\right.$ intelligent $)$ This ADJPP can be turned either into a clause yielding CLAUSE $\left(x_{1}\right.$ be intelligent) (in the XPPtoCLAUSE subgrammar) or it can continue as an adjectival construction (in the ADJPPtoADJPF subgrammar). Tense and Aspect rules determine that the tense of this construction is dependent on the tense of a superordinate construction yet to be formed. A substitu- 
tion rule substitutes the NP containing he for $x_{1}$ yielding ADJPF( he intelligent) and CLAUSE(he is/was intelligent) respectively. Finally Mood rules determine the way the clause and the ADJPF are realized. The mood rule forming subordinate declarative clauses is mapped onto the mood rule forming 'closed' ADJPPs (CADJPP). Applying these mood rules yields SENTENCE(that he is/was intelligent) and $\mathrm{CADJPP}$ (he intelligent). These results can be used later in the derivation as arguments to the verb find.

To derive the rest of the structures the verb find is combined with two variables $\left(x_{2}, x_{3}\right)$ yielding $\operatorname{VPP}\left(x_{2}\right.$ find $\left.x_{3}\right)$. The substructures built earlier can be substituted for $x_{3}$ yielding VPP( $x_{2}$ find he intelligent) and $\operatorname{VPP}\left(x_{2}\right.$ find that he is/was intelligent) respectively. After turning these VPPs into clauses and applying tense and aspect rules (putting the sentences in present tense) the tense of the subordinate clause can be determined. This yields CLAUSE( $x_{2}$ find he intelligent) and CLAUSE( $x_{2}$ find that he is intelligent). Applying a case-assignment transformation and substituting the NP $(I)$ for $x_{2}$ yields CLAUSE( $I$ find him intelligent) and CLAUSE( $I$ find that he is intelligent) respectively. Applying a mood rule that turns these clauses into declarative main clauses yields the actual sentences.

\subsection{Adjective-declarative clause with copula}

The derivations of he seems intelligent, he seems to be intelligent and it seems that he is intelligent starts in the same way as in the preceding section. A CADJPP(he intelligent) and a SENTENCE(that he is/was intelligent) are generated. In addition to the mood rule forming finite declarative subordinate sentences a mood rule forming 'closed' infinite declarative subordinate sentences containing to can be applied. This rule forms the SENTENCE(he to be intelligent) out of the CLAUSE(he be intelligent).

These results can be used as arguments to the verb seem. In the VPPformation subgrammar a $\operatorname{VPP}\left(\right.$ seem $\left.x_{2}\right)$ is formed from the verb seem and the variable $x_{2}$. The SENTENCEs and the CADJPP obtained earlier are substituted for the variable $x_{2}$. This yields the structures $\operatorname{VPP}($ seem he intelligent), VPP(seem that he is/was intelligent) and VPP(seem he to be intelligent) respectively.

A transformation turns the subject of embedded infinitival complements of verbs such as seem into the subject of seem, and the NP(it) is inserted as a subject of the verb seem if it has a finite complement. After determining tense and aspect and applying a subject-verb agreement transformation this yields the structures CLAUSE(he seems intelligent), CLAUSE(it seems that he is intelligent) and CLAUSE(he seems to be intelligent) respectively. Applying the mood rule forming declarative main clauses yields the actual sentences.

In the grammar of Dutch parallel derivations can be made. The CADJPP(hij intelligent) (cf. he intelligent) and the SENTENCEs dat hij intelligent is/was and hij intelligent te zijn (cf. that he is/was intelligent and he to be intelligent resp.) can be derived.

Some of these results can be used as arguments to the verb schijnen 'seem'. In the VPPformation subgrammar the verb schijnen is combined with the variable $x_{2}$ into a $\operatorname{VPP}(x 2$ schijn $)$. The SENTENCEs obtained earlier can be substituted for this variable, but the CADJPP(hij intelligent) cannot, because the Dutch verb schijnen does not take CADJPPs as a complement.

The derivation continues with the two results $\operatorname{VPP}$ (dat hij is/was intelligent schijn) and $\operatorname{VPP}(h i j$ intelligent te zijn schijn). Application of several transformations to deal adequately with such complements in Dutch (Verb-raising and extraposition (in the sense of Evers(1975)), subject-to-subjectraising and some others) and application of tense and aspect rules yields CLAUSE(het schijnt dat hij intelligent is) and CLAUSE(hij intelligent schijnt te zijn) respectively.

Application of mood rules forming declarative main clauses and some obligatory transformations in Dutch yields the actual sentences Het schijnt dat hij intelligent is and $H i j$ schijnt intelligent te $z i j n$ as translations of the English sentences derived earlier.

\subsection{Adjective-relative clause}

The derivations of (de) op haar verliefde (man) (the man in love with her) and (de man) die op haar verliefd is (the man that is in love with her) runs as follows.

The adjective verliefd 'in love' is a two-place adjective that is combined with two variables $x_{1}$ and $x_{2}$ in the ADJPPformation subgrammar. This yields a structure of the form $\operatorname{ADJPP}\left(x_{1}\right.$ verliefd $x_{2}$ ). The adjective verliefd must realize its second argument $\left(x_{2}\right)$ as a prepositional object that can occur in front of the adjective. Pattern transformations introduce the preposition required, yielding $\operatorname{ADJPP}\left(x_{1}\right.$ op $x_{2}$ verliefd $)$. 
This ADJPP can be turned into a clause, or it can be turned into an adjectival phrase. The XPPROPtoCLAUSE subgrammar changes the structure mentioned in the following way: CLAUSE $\left(x_{1}\right.$ op $x_{2}$ verliefd zijn), where the top category has been turned into CLAUSE and the copula zijn 'be' has been introduced. To form an adjectival phrase the ADJPP is input to the XPPtoXPF subgrammar, yielding $\operatorname{ADJPF}\left(x_{1}\right.$ op $x_{2}$ verliefd $)$. In both subgrammars tense and aspect rules apply.

In the CLAUSEtoSENTENCE subgrammar a transformation is applicable that moves the subject variable $x_{1}$ into a position where normally relative pronouns would appear. In this particular structure this has no effects on the left-right order, but the relation that $x_{1}$ bears is clianged.

In the CLAUSEtoSENTENCE subgrammar and in the ADJPFtoADJPP subgrammar the NP(zij) 'she' is substituted for variable $x_{2}$ and the appropriate Case form (accusative) is assigned to it. This yields CLAUSE $\left(x_{1}\right.$ op haar verliefd is/was $)$ and $\operatorname{ADJPP}\left(x_{1}\right.$ op haar verliefd $)$.

Finally Mood rules turn the ADJPP into an 'open' ADJPP (OADJPP) yielding OADJPP $\left(x_{1}\right.$ op haar verliefd), and they turn the CLAUSE into a relative subordinate clause: $\operatorname{SENTENCE}\left(x_{1}\right.$ op haar verliefd is). These structures can be used by rules in the NP-subgrammar that introduce these structures as modifiers and bind variable $x_{1}$.

\subsection{Graag-like}

In the Dutch sentence hij zwemt graag the adverb graag appears. This adverb must be mapped onto the English verb like in the translation he likes to swim.

It is assumed that the Dutch adverb graag is a two place-function. This is required in Rosetta, because its translation like is a two-place function ${ }^{4}$. However, apart from being required in Rosetta, it is also plausible for independent reasons that graag is a two-place function: the adverb graag imposes selectional restrictions upon the subject of the selltence it appears in (cf. Thet regent graag or ?de steen valt graag, which are as odd as their English counterparts Pit likes to rain and SThe stone likes to $\mathrm{fall}$ ). If we assume that predicates impose selectional restrictions only upon their arguments, then it must be the case that the subject of the sentence is an argument of graag, or that the argument of

${ }^{4}$ This contrasts with the approach in the Eurotra framework, where this requirement does not hold. See Arnold et. al. (1988) graag is coindexed with the subject of the sentence. I will assume the latter.

Starting with the subordinate infinitival clause in English, we combine the verb swim, which takes one argument, with a variable $x_{1}$ as its subject, yielding: $\operatorname{VPP}\left(x_{\downarrow}\right.$ swim $)$ Similarly in the Dutch grammar the translation of swim, zwem, is combined with $x_{1}: \operatorname{VPP}\left(x_{1}\right.$ zwem $)$ In the VPPformation subgrammar the voice rule to form active clauses is applied.

After the VPPformation subgrammar the derivation continues in the XPPtoCLAUSE subgrammar. An M-rule to make the sentence infinitival is applied. Corresponding rules are applied in the XPPtoCLAUSE subgrammar of Dutch.

In the CLAUSEtoSENTENCE subgrammar no arguments are substituted. In English a rule is applied that makes the clause an infinitival subordinate clause containing to and containing a free variable in subject position which will later be subject to control transformations. This yields a structure of the form SENTENCE $\left(x_{1}\right.$ to swim)

In Dutch a corresponding rule is applied that makes the clause an infinitival subordinate clause without te with a free variable in subject position. This yields the following structure in Dutch: $\operatorname{SENTENCE}\left(x_{1}\right.$ zwemmen $)$ These structures will be used later on.

In the VPPformation subgrammar of English the two-place verb like is combined with two variables, $x_{1}$ and $x_{2}$. This yields: $\operatorname{VPP}\left(x_{1}\right.$ like $\left.x_{2}\right)$ The voice rule to form active sentences is applied.

Correspondingly, in the ADVPPformation subgrammar of Dutch the adverb graag is combined with two variables, $x_{1}$ and $x_{2}$, and a voice rules is applied. This yields: $\operatorname{ADVPP}\left(x_{1}\right.$ graag $\left.x_{2}\right)$

In the English subgrammar XPPtoCLAUSE the sentential structure derived above is substituted for the variable $x_{2}$, yielding: $\operatorname{VPP}\left(x_{1}\right.$ like $/ x_{1}$ to swim/)

A control transformation deletes the second occurrence of $x_{1}$. Tense and aspect rules apply which turn the structure into a finite clause in present tense.

In the Dutch subgrammar XPPtoCLAUSE the sentential structure derived above is substituted for the variable $x_{2}$ by a special rule that takes care of substitution of sentential complements into AD. VPPs. This special rule deletes the ADVPP node and replaces it by a VPP node, turns the ADVP into a modifier inside this VPP, makes the VP of SENT the VP of this VPP, deletes the variable $x_{1}$ inside SENT and un-does the morphological effects of tense rules. This yields the structure: $\operatorname{VPP}\left(x_{1}\right.$ 
ADVP(graag) zwem)

These structures continue their normal derivation. Tense and aspect rules apply, the NP argument $h i j(h e)$ is substituted for $x_{1}$ and the sentence is made into a declarative main clause, yielding in English: SENTENCE(he likes to swim) and in Dutch, after application of the transformation of 'Verb second' and an obligatory topicalization transformation: SENTENCE( $h i j$ zwemt graag)

\section{CONCLUSION}

It has been shown that the concept of partial isomorphy between subgrammars makes it possible to translate between words of different syntactic categories and between 'small clauses' and full clauses in a systematic way. Furthermore, it has been shown that one of the most difficult cases of translation between words of different categories, viz. the graag/ like translation problem, can be reduced to having only one special rule, given partial isomorphy between subgrammars.

\section{ACKNOWLEDGEMENTS}

This paper is based on joint work being done in the Rosetta machine translation project. I would like to thank Lisette Appelo, Jan Landsbergen, Margreet Sanders and André Schenk for many valuable comments on earlier drafts of this paper.

\section{REFERENCES}

Appelo, L. , C. Fellinger and J. Landsbergen (1987), 'Subgrammars, Rule Classes and Control in the Rosetta Translation System', Philips Research M.S. 14.131, to appear in: Proceedings of Srd Conference ACL, European Chapter.

Appelo, L. and J. Landsbergen (1986), 'The Machine Translation Project Rosetta', Philips Research M.S. 13.801, In: Proceedings First International Conference on the State of the Art in Machine Translation, Saarbrücken, pp. 34-51.

Arnold, D., S. Krauwer, L. des Tombe \& L. Sadler (1988), "Relaxed' Compositionality in Machine Translation', in: Proceedings of the Second International Conference on Theoretical and Methodological Issues in Machine Translation of Natural Languages, Carnegie Mellon University, Center for Machine Translation, Pittsburgh, Pennsylvania.

Evers, A. (1975), The Transformational Cycle in Dutch and German, diss. University of Utrecht.

Landsbergen, J. (1987), 'Isomorphic grammars and their use in the Rosetta Translation System', Philips Research M.S. 12.950, Paper presented at the Tutorial on Machine Translation, Lugano, 1984, in: M. King (ed.), $M a-$ chine Translation, the State of the Art, Edinburg University Press.

Leermakers, R. and J. Rous (1986), 'The Translation Method of Rosetta', Philips Research M.S. 13.701, In: Computers and Translation, Vol 1, number 3, pp. 169-183.

Stowell, T. (1981), Origins of Phrase Structure, $\mathrm{Ph}$. D. dissertation, MIT. 